\title{
Metals used in old Bridges in Sri Lanka and the Effects of their Material Properties on Capacity Estimations
}

\author{
C.S. Bandara, J.A.S.C. Jayasinghe, P.A.K. Karunananda and U.I. Dissanayake
}

\begin{abstract}
Most of the metal bridges that were built over 100 years ago are still in use in Sri Lanka. To ensure the safety of these bridges as well as their users, condition assessment of these old structures becomes essential. The details of these bridges such as their mechanical and fatigue properties and the types of materials used in these bridges are very important for assessing their condition. Therefore, this study on metals used in old bridges was carried out using a literature survey and our own experiments. Recommendations were given thereafter for the selection of the mechanical and fatigue properties that are appropriate for assessing the old metal bridges in the country. The recommended values for the ultimate tensile strength of wrought iron and mild steel are in the ranges $284-390 \mathrm{~N} / \mathrm{mm}^{2}$ and $370-450 \mathrm{~N} / \mathrm{mm}^{2}$ respectively; values of yield strength of wrought iron and mild steel are in the ranges $191-241 \mathrm{~N} / \mathrm{mm}^{2}$ and $220-280 \mathrm{~N} / \mathrm{mm}^{2}$ respectively and, mean fatigue strength at 10 million cycles for both wrought iron and mild steel is $190 \mathrm{~N} / \mathrm{mm}^{2}$. Finally, the importance of selecting appropriate mechanical properties for estimating the current carrying capacity of metal bridges is presented using examples. It is observed that the error in the estimation of the carrying capacity of a bridge resulting from the use of inappropriate mechanical properties could be as high as $33 \%$.
\end{abstract}

Keywords: Metal bridge, wrought iron, mild steel, material properties, condition assessment

\section{Introduction}

Metal bridges had been introduced to Sri Lanka in the $19^{\text {th }}$ century with the development of its road and railway transport network [1, 2]. Even after 10 - 15 decades, most of these metal bridges are still in use. The fact that several old metal bridges such as "KaluPalama Bridge" on Galle - Deniyaya - MadampeRoad and "Meeliyadda Bridge on Kurunegala KeppitigalaRoad collapsed in the recent past, highlights the need for assessing the condition of old metal bridges in the country.

The bridge assessment process needs material properties of the bridge such as its composition microscopic details and its mechanical and fatigue properties $[3,4]$. These details are useful for identifying the metal used in the bridge, estimating the strength and understanding the behaviour of the material during loading. They are useful in condition assessments for determining the load carrying capacity, remaining life and failure mechanisms of structural members such as ductile or brittle fracture and fatigue failure.

The determination of the material properties of a bridge needs testing of its metal specimens obtained from different structural members. The material properties of a bridge may differ from one member to another depending on the production quality of the old metals [5], possible member replacements and material degradation due to fatigue and corrosion [6, 7].

Therefore to obtain material properties of an old bridge accurately, a large number of samples taken from different parts of the structure have to be tested which would certainly be a difficult task. Furthermore, if the samples do not represent the material properties of the entire bridge correctly, it may produce erroneous assessment results.

Some knowledge on the material properties of other metal bridges built during the same era will definitely assist in reducing the errors or the uncertainties relating to the material properties of any particular bridge.

Eng. (Dr.) C. S. Bandara, AMIE(Sri Lanka), B.Sc. Eng. (Peradeniya), M.Sc. Eng. (Peradeniya), PhD. (Peradeniya), Senior Lecturer, Department of Civil Engineering, Faculty of Engineering, University of Peradeniya.Email:chamindasbandara@yahoo.com

Eng. (Dr.) J. A. S. C. Jayasinghe, AMIE(Sri Lanka), B.Sc Eng. (Peradeniya), M. Eng. (AIT), Ph.D. (Tokyo), Senior Lecturer, Department of Civil Engineering, Faculty of Engineering, University of Peradeniya.

Email:supunj@pdn.ac.lk

Eng. (Dr.) P. A. K. Karunananda, C. Eng., MIE(Sri Lanka), B.Sc. Eng. (Peradeniya), M. Phil. (Peradeniya), M. Phil. (Ehime), D. Eng. (Ehime), Senior Lecturer,

Department of Civil Engineering, Open University of Sri Lanka.Email:pakar@ou.ac.lk

Eng. (Dr.) U. I. Dissanayake, C. Eng., MIE(Sri Lanka), B.Sc. Eng. (Peradeniya), Ph.D. (Sheffield), Senior Lecturer, Department of Civil Engineering, Faculty of Engineering, University of Peradeniya.Email:udissa@pdn.ac.lk 
The first aim of this paper was to provide the important material properties of old ferrous metals used in bridge construction during the period from $19^{\text {th }}$ century to early part of $20^{\text {th }}$ century. In this study, material properties were obtained from the literature and also by testing the metals of several bridges.

It is important for engineers to understand the magnitude of the error that can result from the inappropriate selection of material properties in the assessments of old bridges. As the next aim of this paper, the load carrying capacities of two metal bridges were estimated by changing the metal type and its mechanical properties. Then, the percentage error in the capacity estimation was evaluated.

\section{Methodology}

Material properties of existing metal bridges were studied in two steps: (a) conducting laboratory tests using metals obtained from different bridges (built in the 19thand early $20^{\text {th }}$ centuries) in the country. Tensile, hardness and fatigue tests were carried out to estimate strength properties while microscopical investigations were conducted to identify the metal, (b) studying the literature related to materials in old metal bridges. Local literature was used directly to obtain the material details of the bridges in the country while literature published in other countries was used to compare the properties of metals used in those countries in the $19^{\text {th }}$ and early $20^{\text {th }}$ centuries. The details obtained during these two steps were then analysed and a reasonable estimation of material and strength properties was made.

Material testing was carried out for randomly selected (or received from bridge authorities) samples. The standards used were ASTM E $8 \mathrm{M}$ - 01: 2001 for the tensile test [8], ASTM E 18 M 02 for the Rockwell hardness test [9] and BS 3518: 1962 for the fatigue test [10].

In order to estimate the magnitude (percentage) of the error caused by the inappropriate selection of material properties, Finite Element Models (FEMs) of two metal truss bridges were employed. The load carrying capacity of each bridge was estimated for four types of materials: (1) wrought iron - low strength (WI/L), (2) wrought iron - high strength (WI/H), (3) mild steel - low strength (MS/L) and (4) mild steel - high strength (MS/H). Then, the carrying capacities were compared and the percentage error was estimated.

\section{Literature Survey on Metal Bridges in Europe and USA}

Literature shows that the three main metals used in road and railway bridges during the period from the $18^{\text {th }}$ century to early $20^{\text {th }}$ century were cast iron, wrought iron and mild steel. Much needed information about these three metals is available in some of the recently published literature $[5,11,12,13,14]$.

Cast iron has been used in bridge construction since the $18^{\text {th }}$ century. The Iron-bridge at Colebrookdale, United Kingdom built during the period 1777 - 1779 is the world's first major cast iron bridge [15]. Cast iron contains over $2 \%$ carbon and thus is not weldable. Graphite flakes make cast iron brittle. Internal cracks can occur and propagate along these flakes due to tensile stresses and cast iron therefore is weak in carrying tensile and impact loads. However, cast iron has a good wear resistance making it a favoured metal for the bearing plates of many metal bridges. Tests conducted in 1969 on specimens taken from the Colebrookdale Ironbridge showed that the Ultimate Tensile Strength (UTS) of cast iron is as low as 131 $\mathrm{N} / \mathrm{mm}^{2}$ and that its compressive strength is 208 $\mathrm{N} / \mathrm{mm}^{2}[15]$.

With the commencement of its production in the late $18^{\text {th }}$ century, wrought iron (puddle steel) became a popular material for the superstructure of bridges due to its good tensile properties. The carbon content of wrought iron is less than $0.08 \%$. The high amounts of prosper and nitrogen contained in wrought iron make it a brittle material. Wrought iron also contains slag layers (sulphates and oxides) deposited during its production. The weldability of wrought iron is also low necessitating the use of rivets to connect wrought iron members. One of the best-known wrought iron structures is the Eiffel Tower in France built during the period 1887 - 1889. According to Bowman and Piskorowski [11], the experimental work of Kiraldy, Humber and Beardslee conducted in 1860s showed that the average UTS, Yield Strength (YS) and Elongation (EL) of wrought iron were $372 \mathrm{~N} / \mathrm{mm}^{2}, 228 \mathrm{~N} / \mathrm{mm}^{2}$ and $23.2 \%$ respectively.

The production of mild steel in the 1850s made a huge change in the metal industry due to the strength, ductility, impact resistance and weldability of mild steel. Therefore, in the early $20^{\text {th }}$ century, mild steel was the main material used for metal bridges. The early mild steel produced in the $19^{\text {th }}$ century contained many 
Table 1- Chemical composition and mechanical properties of old metals used in bridges

\begin{tabular}{lllllllll}
\hline \multirow{2}{*}{ Description } & \multicolumn{3}{l}{ Chemical Composition (\%) } & \multicolumn{3}{l}{ Mechanical Properties } \\
\cline { 2 - 10 } & $\mathrm{C}$ & $\mathrm{Mn}$ & $\mathrm{Si}$ & $\mathrm{S}$ & $\mathrm{P}$ & $\mathrm{UTS}$ & YS & EL \\
\hline Cast iron & $>2.0$ & $0.2-1.2$ & $0.3-3.0$ & $<1.2$ & $<1.0$ & $90-135$ & 0 \\
\hline Wrought iron & $0.08-1.0$ & $<0.4$ & & $<0.04$ & $<0.6$ & $280-400$ & $220-310$ & $5-20$ \\
\hline Mild steel (before 1900) & $0.02-0.15$ & $0.2-0.5$ & 0.08 & $0.02-0.15$ & $0.03-0.07$ & $370-440$ & $>220$ & $\approx 20$ \\
\hline Mild steel (1900 - 1940s) & $0.1-0.2$ & $0.4-0.5$ & 0.08 & 0.01 & & $370-450$ & $240-280$ & $15-25$ \\
\hline
\end{tabular}

Note: UTS: Ultimate Tensile Strength in $\mathrm{N} / \mathrm{mm}^{2}$, YS: Yield Strength in $\mathrm{N} / \mathrm{mm}^{2}$, EL: percentage elongation at fracture

impurities due to which the variation of its mechanical properties was high. However, mild steel produced in the $20^{\text {th }}$ century was reasonably good in quality.

JRC Report [5] provides details on the chemical composition and mechanical properties of metals used in old metal bridges in Europe. These details are reproduced in Table 1.

The mechanical properties recommended in the JRC Report [5] for YS of old mild steel in Europe is $230 \mathrm{~N} / \mathrm{mm}^{2}$ and it was 200 $\mathrm{N} / \mathrm{mm}^{2}$ for wrought iron with the Young's modulus standing at $210 \mathrm{GPa}\left(\mathrm{at}+10^{\circ} \mathrm{C}\right)$ for both metals. Larsson [9], considering the

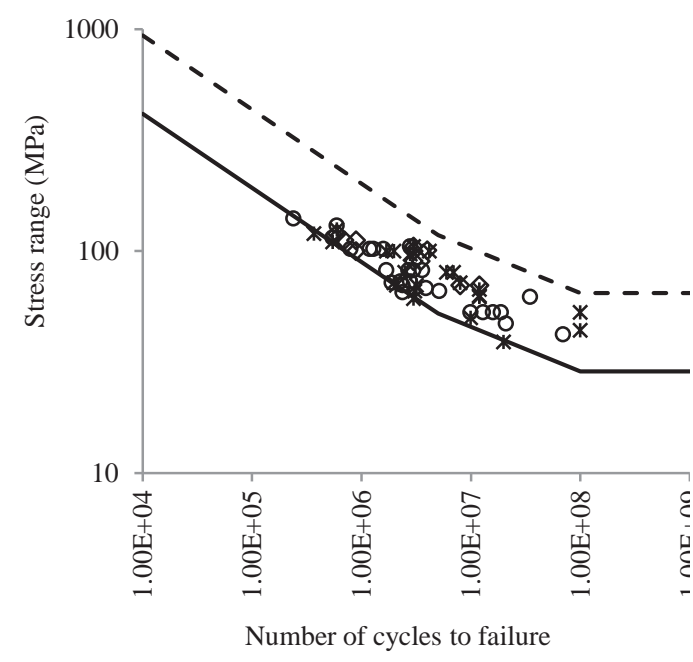

$\diamond \quad$ Fatigue tests on wrought iron plate and truss girders [Larsson, 2009]

* Fatigue tests on corroded plate girders [Larsson, 2009]

o Fatigue test on riveted connections [El Aghoury, 2012]

- - - EN1993-1-9: Detail C160

— EN1993-1-9: Detail C71

Figure 1 - Full scale fatigue tests data and Detail C71: S-N curve recommended for old metal bridges (Log - Log Plot) experimental data (tested at $0^{\circ} \mathrm{C}$ to $-30^{\circ} \mathrm{C}$ ) of old bridges built in Sweden and Germany, has mentioned that the characteristic YS and UTS of mild steel in bridges built between 1919 and 1940 is $220 \mathrm{~N} / \mathrm{mm}^{2}$ and $350 \mathrm{~N} / \mathrm{mm}^{2}$ respectively and that the strength reduction for bridges built between 1901 - 1919 should be $20 \%$ and that for bridges built before 1900it should be $45 \%$. Berman et al.[11]have stated that the recommended shear strength for rivets in bridges built before 1936 in the USA is 124 $\mathrm{N} / \mathrm{mm}^{2}$.

Fatigue properties are the other material properties important in metal bridges. The Stress - Life (S-N curve) proposed in the JRC Report [5] for fatigue damage assessments of old riveted wrought iron and mild steel bridges is the Detail C71 curve of EN 1993-1-9: 2005 [16]. Figure 1 shows the comparison between Detail C71: S-N curve and the actual full scale fatigue test data obtained from the literature $[12,17]$.

\section{Studies done on the Metal Bridges in Sri Lanka}

The three major metals used in road and railway bridges in Sri Lanka before mid-20th century were cast iron, wrought iron and mild steel. The Transactions of the Engineering Association of Ceylon published during the period from 1908to 1939 [18, 19, 20, 22] show that cast iron had been widely used for bridge piers and bearing plates. Buckle [19], mentions that the road bridge between Mannar Island and the mainland had piers built with cast iron outer cylinders, wrought iron inner cylinders with concrete filling the gap between the cylinders. The study made by Siriwardane et al. [3] shows that the piers of Kelani Railway Bridge built in 1885 are made of cast iron filled with concrete. 
Table 2 - Mechanical and fatigue properties of iron and steel in bridges built before mid-20th century in Sri Lanka

\begin{tabular}{|c|c|c|c|c|c|c|c|c|}
\hline Name of the bridge & $\begin{array}{l}\text { Age } \\
\text { (years) }\end{array}$ & Specimen location & Material & UTS & YS & EL & HRB & FS \\
\hline KelaniRailway Bridge & $>130$ & $\begin{array}{l}\text { Diagonal truss } \\
\text { member }\end{array}$ & Wrought iron & 328 & 241 & 17 & 57 & 165 \\
\hline BattuluoyaRoad Bridge & $>100$ & $\begin{array}{l}\text { Diagonal truss } \\
\text { member }\end{array}$ & Wrought iron & 343 & 230 & 17 & 58 & 160 \\
\hline BattuluoyaRoad Bridge & $>100$ & Rivet & Wrought iron & 390 & -- & -- & 67 & -- \\
\hline RakwanaRoad Bridge & $>100$ & Truss member & Wrought iron & 284 & 191 & 16 & 63 & -- \\
\hline RakwanaRoad Bridge & $>100$ & Angle connector & Wrought iron & 337 & 212 & 20 & -- & -- \\
\hline RakwanaRoad Bridge & $>100$ & Bolt & Wrought iron & 341 & 239 & 21 & -- & -- \\
\hline KatugastotaRoad Bridge & $>150$ & Main lattice member & Wrought iron & 338 & 229 & 18 & -- & -- \\
\hline KelaniRailway Bridge & $>130$ & Pier & Cast iron & 165 & & & & \\
\hline SenarathgamaRailway Bridge & $>100$ & $\begin{array}{l}\text { Lattice connecting } \\
\text { plate }\end{array}$ & Mild steel & 434 & 302 & 29 & 65 & 205 \\
\hline MaggonaRailway Bridge & $>100$ & Plate girder & Mild steel & 552 & 406 & 21 & -- & 260 \\
\hline NarahenpitaRailway Bridge & $>100$ & Girder & Mild steel & 426 & 250 & 37 & 67 & 200 \\
\hline MeeliyaddaRoad Bridge & $>100$ & Gusset plate & Mild steel & 372 & 233 & 30 & 68 & -- \\
\hline
\end{tabular}

Wrought iron was the mostly used metal for the superstructure of bridges built before 1900 . Bridges such as the KatugastotaRoad Bridge built in 1860 [21], WarakatotaRoad Bridge on Colombo - Ratnapura - HalpeRoad built in 1863 [20], PeradeniyaRailway Bridge built in 1867 [6], KelaniRailway Bridge built in 1885 [3], GalbodaRailway Bridge built in 1885 [6] and KanganinanodeiRoad Bridge in Kalmunai built in 1904 [18] had been originally built with wrought iron.

Mahadeva[21] states that the KatugastotaRoad Bridge was strengthened in 1905 by adding new truss girders below the existing trusses that were made of mild steel. According to Hyde [20], the main span of WarakatotaRoad Bridge was replaced in 1913 with new bowstring trusses made of mild steel. Wijeyesekera [6] mentions that PeradeniyaRailway Bridge was strengthened using steel members after it was damaged by floods in 1947 and that one span of the GalbodaRailway Bridge was replaced with mild steel plate girders in 1950. These show the transformation of superstructure materials of bridges in Sri Lanka from wrought iron to mild steel. This further verifies the possibility that both wrought iron and mild steel can be found in a single bridge.
Some resent studies done on old metal bridges in Sri Lanka such as the fatigue damage assessment of KelaniRailway Bridge [3], reliability based life prediction of wrought iron bridges [22], condition assessment of metal railway bridges [23, 24, 25, 26], finite element analysis of truss type steel bridges [27] and retrofitting of damaged bridges [4]can be found in the literature. However, most of these studies mainly discuss the assessment processes and do not focus much on material details.

\section{Details of Metals used in old Bridges in Sri Lanka}

The mechanical and fatigue properties (mean values) of the metals used in the bridges built in Sri Lanka before mid-20th century are given in Table 2. Microscopical investigations show that the materials of all tested bridges are cast iron, wrought iron or mild steel. Figure 2 shows the wrought iron and mild steel microstructure of some of the bridges in the country. Figure 3 shows the fracture surface of wrought iron and mild steel formed when subjected to the rotary bending fatigue test. The brittle fracture surface of wrought iron and smooth crack propagation of mild steel are visible in this figure. All the tests except the one on KatugastotaRoad Bridge, were carried out at the Faculty of Engineering, University of Peradeniya(test data 

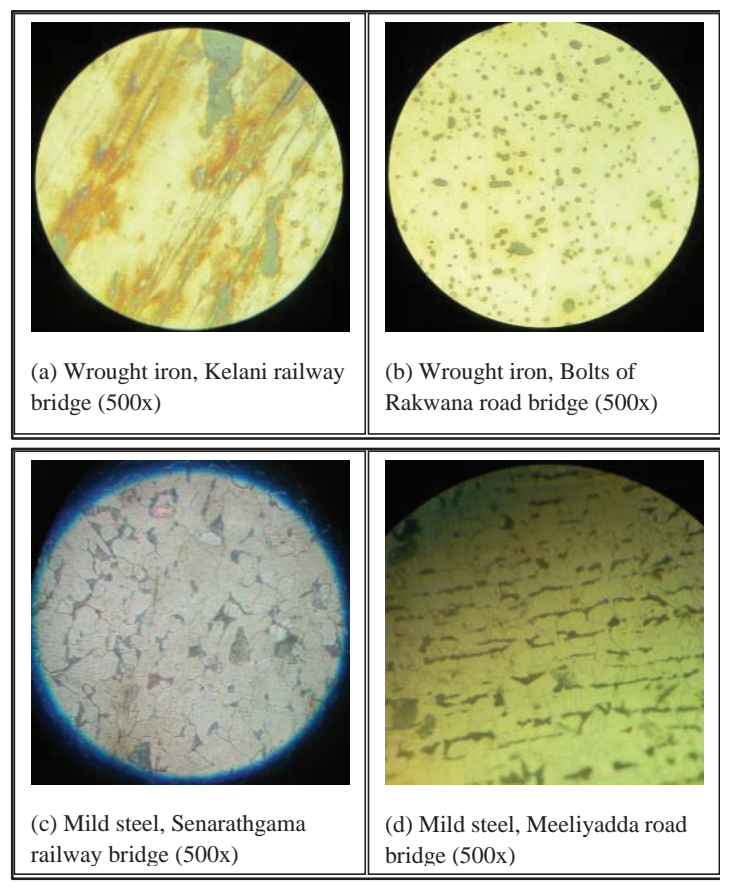

Figure 2 - Microstructure of old metals: (a) and (b) show wrought iron microstructure: Ferritic, inhomogeneous grain distribution with oxides and slag, (c) and (d) show mild steel microstructure: Ferritic - Pearlitic, homogeneous grain distribution.

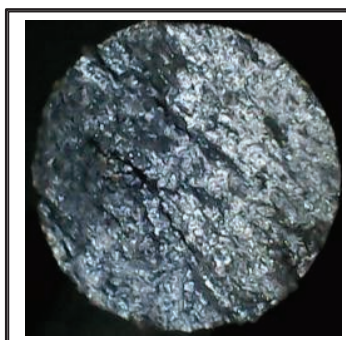

(a) Diameter $6 \mathrm{~mm}$ wrought iron fatigue specimen failed at 11 million cycles (Battuluoya road bridge material)

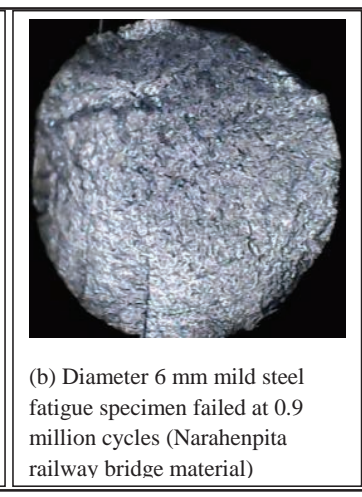

Figure 3 - Fracture surface of fatigue specimens, (a) brittle like fracture in wrought iron, (b) clear and smooth crack propagation and fracture in mild steel

of KatugastotaRoad Bridge was obtained from Mahadeva[21]).

\subsection{Mechanical Properties}

A statistical evaluation was carried out using the experimental data of 45 tensile specimens (the mean values of some of them are given in Table 2) to determine the values for UTS and YS of both mild steel and wrought iron used in the country. It was observed that the mean value of UTS is $372 \mathrm{~N} / \mathrm{mm}^{2}$ and that the mean value of YS is $256 \mathrm{~N} / \mathrm{mm}^{2}$. Statistical evaluation showed that the Standard Deviation (SD) for UTS is 62 $\mathrm{N} / \mathrm{mm}^{2}$ and that it is $44 \mathrm{~N} / \mathrm{mm}^{2}$ for $\mathrm{YS}$. Figures 4 and 5 show the tensile test results, mean

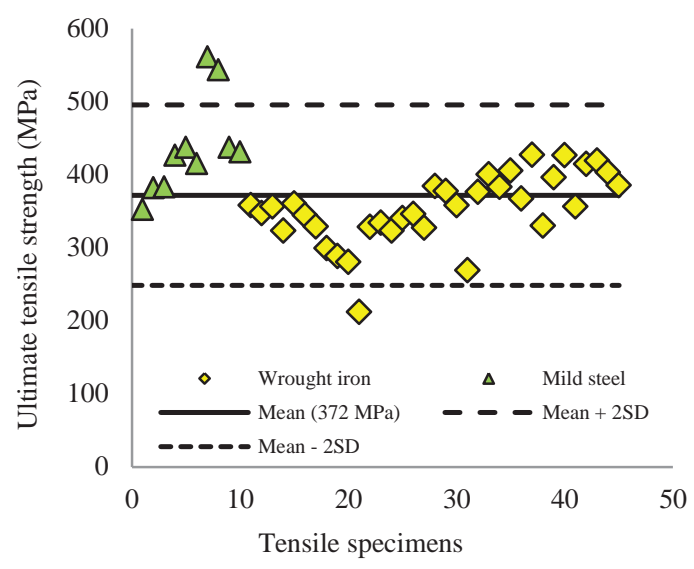

Figure 4 - Variation of ultimate tensile strength of wrought iron and mild steel

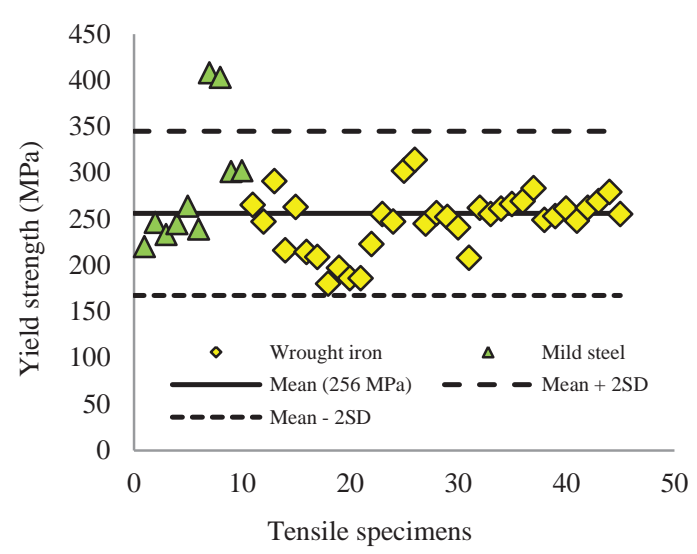

Figure 5 - Variation of yield strength of wrought iron and mild steel

values and $2 \times$ SD limits (for 95\% confidence). Statistical evaluation shows that "Mean $-2 \times$ $\mathrm{SD}^{\prime \prime}$ values are sufficiently safe for the assessment of old metal bridges in the country. However, for critical bridges and detailed assessments, at least a few samples may be tested for further verification.

Experimental values for Young's modulus of wrought iron and mild steel can be found in the literature. The tensile test carried out on the wrought iron obtained from Kelani and other bridges shows that the Young's modulus of wrought iron is $195 \mathrm{GPa}[3,25]$. The Young's modulus of the mild steel of Senarathgama and MaggonaRailway Bridges is $200 \mathrm{GPa}[23,24]$.

\subsection{Fatigue Strength}

The fatigue strength of wrought iron and mild steel was investigated for High Cycle Fatigue (HCF)using more than 40 specimens. The required material was obtained from three wrought iron bridges and 3 mild steel bridges. Fatigue test was carried out at the Faculty of Engineering, University of Peradeniya using a constant amplitude rotary bending fatigue 
tester. Figure 6 shows the S-N curve developed from the test results, the mean S-N line and \pm $20 \%$ lines. The mean fatigue strength at 10 Million cycles is $190 \mathrm{~N} / \mathrm{mm}^{2}$. The $-20 \% \mathrm{~S}-\mathrm{N}$ line seems safe for fatigue life assessments. However, the variable amplitude nature of actual loading cycles, stress concentration and corrosion effects will have to be considered when determining the actual fatigue strength.

\section{Effects of Material Properties on Capacity Estimations of Bridges}

Structural assessments are very important for bridges that have been in use beyond their design lives or for bridges that have been subjected to increased service loading far above the design service loading and to deteriorations such as corrosion and accidental loading. In structural assessments, the identification of the metal type and the determination of the appropriate material properties such as mechanical and fatigue properties are very important. In order to investigate the effect of mechanical properties on loading capacity assessments, two common types of metal truss bridges were used in this study. The truss type in Bridge 1 is Pratt truss and that in Bridge 2 is Double Warren truss. The Finite Element Models (FEM) of these two truss bridges are shown in Figure 7. The four steps involved in this capacity estimation are discussed below.

Step 1:The materials of both bridges (FEMs) were considered as wrought iron. The Young's modulus (195 GPa) of wrought iron was assigned for the FEMs. Poisson's ratio used was 0.3. Then, the low strength values of wrought

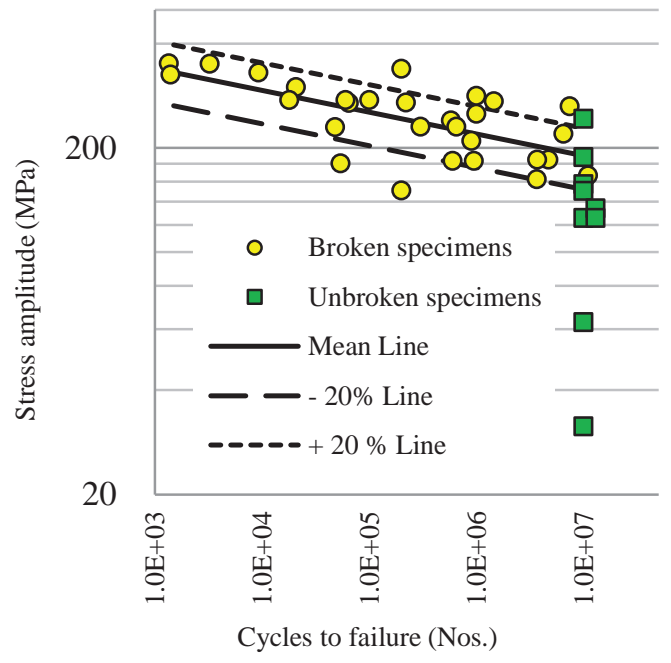

Figure 6 - Fatigue strength variation of wrought iron and mild steel (on Log - Log Plot) iron (denoted as WI/L in Table 3) were assigned to FEMs. Both bridges were loaded with a Uniformly Distributed Load (UDL). The UDL was increased until the first member of each bridge failed. The UDL values at the time of this failure were recorded as the carrying capacities of the bridges (Table 4).
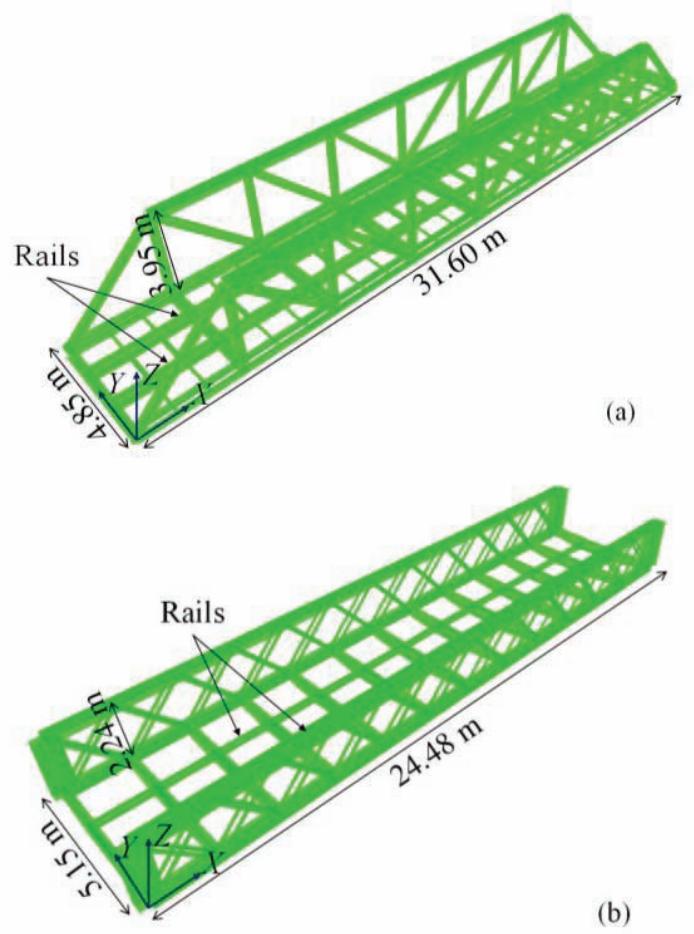

Figure 7 - Target steel bridge structures: (a) bridge-1: Pratt Truss and (b) bridge-2: Double Warren Truss

Table 3 - Material details and strength values assigned to FEMs

\begin{tabular}{lcc}
\hline Material & Mild steel & $\begin{array}{c}\text { Wrought } \\
\text { iron }\end{array}$ \\
\hline Young's Modulus E (GPa) & 200 & 195 \\
Poisson's Ratio $v$ & 0.3 & 0.3 \\
\hline Low Strength & MS/L & WI/L \\
\hline Minimum UTS (N/mm²) & 335 & 256 \\
Minimum YS (N/mm²) & 210 & 172 \\
Average UTS (N/mm²) & 372 & 284 \\
Average YS (N/mm²) & 233 & 191 \\
\hline High Strength & MS/H & WI/H \\
\hline Minimum UTS (N/mm²) & 497 & 309 \\
Minimum YS (N/mm²) & 365 & 217 \\
Average UTS (N/mm²) & 552 & 343 \\
Average YS (N/mm²) & 406 & 241 \\
\hline
\end{tabular}


Step 2:Without changing the material, high strength values of wrought iron (denoted as $\mathrm{WI} / \mathrm{H}$ in Table 3) were assigned to FEMs. A loading procedure similar to that of Step 1 was followed and the carrying capacities of both bridges were recorded (given in Table 4).

Step 3:The materials of both bridges were changed to mild steel by changing the Young's modulus (200 GPa) of the FEMs. Then, low strength values of mild steel (denoted as MS/L in Table 3) were assigned to the FEMs. The same loading procedure similar to that of Step 1 was followed and the carrying capacities of both bridges were recorded (given in Table 4).

Step 4: Without changing the material, high strength values of mild steel (denoted as MS/H in Table 3) were assigned to the FEMs. The loading procedure was similar to that of previous steps. Then, the carrying capacities of both bridges were recorded (given in Table 4).

Figure 8 shows the vertical ( $\mathrm{z}$ direction) displacement of the bridges. In Bridge 1, the overstressed bridge members (Pratt Truss) were the middle top code members and in Bridge 2 (Double Warren Truss) the diagonal truss members close to the supports were the overstressed bridge members.
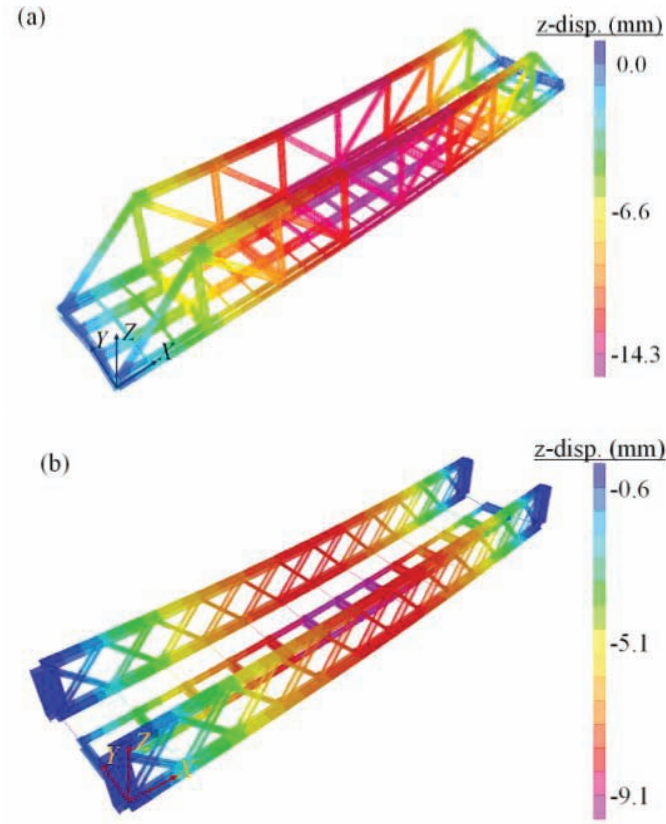

Figure 8 - Displacement in the z-direction (zdisp.) of bridge structures for MS/H material selection due to applied distrusted load along rails: (a) Bridge- 1 and (b) Bridge- 2
Table 4 - Capacities of bridges and the maximum percentage error subjected to materials and the strength values assigned to FEMs

\begin{tabular}{cccc}
\hline $\begin{array}{c}\text { Bridge } \\
\text { Number } \\
\text { and Type }\end{array}$ & Material Type & $\begin{array}{c}\text { Load } \\
\text { Capacity } \\
(\mathrm{kN} / \mathrm{m})\end{array}$ & Error (\%) \\
\hline WI/L & 13.50 & 0.00 \\
$\begin{array}{c}\text { Bridge 1 } \\
\text { (Pratt truss) }\end{array}$ & $\mathbf{W I / H}$ & 14.75 & 9.26 \\
$\mathbf{M S} / \mathbf{L}$ & 16.00 & 18.52 \\
\hline $\begin{array}{c}\text { Bridge 2 } \\
\text { (Double }\end{array}$ & $\mathbf{M I} / \mathbf{H}$ & 18.00 & 33.33 \\
$\begin{array}{c}\text { Warren } \\
\text { truss) }\end{array}$ & $\mathbf{M S} / \mathbf{L}$ & 8.25 & 0.00 \\
& $\mathbf{M S} / \mathbf{H}$ & 9.25 & 12.12 \\
\hline
\end{tabular}

As shown in Table 4, if the material of Bridge 1 is wrought iron with low strength and if mild steel with high strength is used by error in the FEM, the error in the carrying capacity could be $33.3 \%$. If this same material selection error happens in Bridge 2, the error of the carrying capacity could be $36.4 \%$. Therefore, this investigation highlights the importance of using correct material properties in the assessments.

\section{Discussion and Conclusions}

The recent collapses of old metal bridges in Sri Lanka show the need for assessing the old bridges. The material properties of these old structures are among the most important data required for the assessments. The present study provides these much needed material properties of metals used in the country from the $19^{\text {th }}$ to early $20^{\text {th }}$ centuries.

The comparison of the mechanical properties shows that the UTS values of wrought iron used in the bridges in the country (i.e. $284-390$ $\mathrm{N} / \mathrm{mm}^{2}$ ) fall within the range found in the literature (i.e. $280-400 \mathrm{~N} / \mathrm{mm}^{2}$ ). However, the value of YS of wrought iron used in the local bridges does not agree with the values given in the literature. Therefore, a value within the range $191-241 \mathrm{~N} / \mathrm{mm}^{2}$ found by testing the wrought iron of local bridges can be recommended for the YS. The UTS of mild steel of local bridge materials is in the range $372-$ $552 \mathrm{~N} / \mathrm{mm}^{2}$ and the lower value is within the range provided in the literature (i.e. $370-450$ $\mathrm{N} / \mathrm{mm}^{2}$ ). The lower value of the range of YS of mild steel of local bridges $\left(233-406 \mathrm{~N} / \mathrm{mm}^{2}\right)$ slightly deviates from the range given in the literature (i.e. $220-280 \mathrm{~N} / \mathrm{mm}^{2}$ ). Statistical 
evaluation shows that the mean UTS of both wrought iron and mild steel is $372 \mathrm{~N} / \mathrm{mm}^{2}$ with a SD of $62 \mathrm{~N} / \mathrm{mm}^{2}$. It also shows that the mean YS of each of the two metals is $256 \mathrm{~N} / \mathrm{mm}^{2}$ with a SD of $44 \mathrm{~N} / \mathrm{mm}^{2}$. The study shows that "Mean - $2 \times$ SD" provides safe strength estimations.

The results of the constant amplitude rotary bending fatigue tests conducted using metals obtained from the bridges in Sri Lanka show that the fatigue strength of wrought iron at 10 million cycles is about $160 \mathrm{~N} / \mathrm{mm}^{2}$ with the fatigue strength of mild steel varying between 200 and $260 \mathrm{~N} / \mathrm{mm}^{2}$. The mean fatigue strength of old metals (i.e. wrought iron and mild steel) at 10 million cycles is $190 \mathrm{~N} / \mathrm{mm}^{2}$. However, a $20 \%$ reduction is needed to estimate a reasonably safe value for the fatigue strength (and S-N curves). Furthermore, the effects of variable amplitude loading, stress concentration and corrosion etc., also have to be taken in to account. As suggested in the literature, it can be mentioned that the Detail C71: S-N curve of EN 1993-1-9: 2005 [16]can also be used for fatigue damage assessments of metal bridges in the country.

The present study shows the significance of selecting appropriate material properties for bridge assessments. The investigation carried out using two truss bridges showed that the error in the estimation of the carrying capacity caused by the material details of a bridge could be as high as $33 \%$. Therefore, the material properties recommended in this study or obtained from material tests should be used for assessing old metal bridges.

There are many other material properties such as fracture toughness, cyclic softening and hardening parameters, gigacycle fatigue properties, deterioration behaviour of old metals due to corrosion and corrosion fatigue that will be useful for the assessment of old metal bridges. These material properties are not available at present for the old structures in the country and therefore it will be essential to conduct further studies on this subject in the future.

\section{Acknowledgement}

Emeritus Prof. M. P. Ranaweera and the team that has been working on railway bridge assessment projects since 1998. Prof. P. B. R. Dissanayake and research team members.
National Research Council, Grant NRC 11-106 and NRC 15 - 127.

\section{References}

1. Gribble, C., "Stresses in Railway Bridges", Transactions of the Engineering Association of Ceylon, 1951, pp. 265-285.

2. Rampala, B. D., Ceylon Government Railway 1864 1964, Government Press, Ceylon, 1964, 174 p.

3. Siriwardane, S. C., Ohga, M., Dissanayake, R., \& Taniwaki, K., "Different Approaches for Remaining Fatigue Life Estimation of Critical Members in Railway Bridges", Steel Structures, Vol. 2007: 7, 2007, pp. 263-276.

4. Dissanayake, R., \& Bandara, C. S., "Retrofitting of Damaged Bridges - the Sustainable Solution", Taylor \& Francis, 2016, DOI: 10.1080/12265934.2016.1138877.

5. JRC Report, Assessment of existing steel structures: Recommendations for estimation of remaining fatigue life, Joint report CEN/TC 250, $1^{\text {st }}$ ed., European commission, Luxembourg, 2008, 98 p.

6. Wijeyesekera, E. C., "Repair and Renewal of Bridges and Culverts under Railway Traffic Conditions", Transactions of the Engineering Association of Ceylon, 1954, pp. 192-212.

7. Bandara, C., Fatigue Damage Assessment of Steel Structures and Components, Lambert Academic Publishing, Germany, 2015, 192 p.

8. ASTM E 8 - 01: 2001, Standard Test Method for Tension Testing of Metallic Materials, ASTM International, PA, 22.

9. ASTM E 18 - 02: 2002, Standard Test Method for Rockwell Superficial Hardness of Metallic Materials, ASTM International, PA, 15 p.

10. BS 3518: 1962, Methods of Fatigue Testing: Part 2 Rotating Bending Fatigue Test, BSI Institution, London, $10 \mathrm{p}$.

11. Bowman, M. D., \& Piskorowski, A. M., Evaluation and Repair of Wrought Iron and Steel Structures in Indiana, JTRP Technical Reports, Purdue University, USA, 2004, 220 p.

12. Larsson, T., Fatigue assessment of riveted bridges, $\mathrm{PhD}$ Thesis, Lules University of Technology, Sweden, 2009,250 p.

13. Berman, J. W., Roeder, C. W., Wang, B. S., Olson, A. W., \& Lehman, D. E., Triage Evaluation of Gusset Plates in Steel Truss Bridges, Washington State Department of Transportation or Federal Highway Administration, USA, 2010, 82 p. 
14. Akesson, B., Fatigue life of riveted steel bridges, $1^{\text {st }}$ ed., CRC press, UK, 2010, 130 p.

15. Miller, J., "The Iron-bridge, Desk Study and Engineering Assessment", ICE Proceedings, Vol. 168, No. EH4, 2015, pp. 177 - 185.

16. EN 1993-1-9 (2005), Design of steel structures: Part 1-9: Fatigue, CEN, Belgium, 37 p.

17. El Aghoury, I., Numerical tool for fatigue life prediction of corroded steel riveted connections using various damage models, PhD Thesis, Concordia university, Canada, 2012, 208 p.

18. Chapman, T. H., "Kanganianodei Bridge, Kalmunai", Transactions of the Engineering Association of Ceylon, 1908, pp. 01-08.

19. Buckle, A. S., "Cylinder bridges", Transactions of the Engineering Association of Ceylon, 1912, pp. 2248.

20. Hyde, G. H. M., "Warakatota Bridge", Transactions of the Engineering Association of Ceylon, 1913, pp. 07-39.

21. Mahadeva, S., "Reconstruction of Katugastota Bridge", Transactions of the Engineering Association of Ceylon,1939, pp. $23-44$.

22. Dissanayake, P. B. R., \& Karunananda, P. A. K., "Remaining Service Life Prediction of Riveted Wrought Iron Railway Bridges using System Reliability Approach", J. of Nat, Sci. Foundation Sri Lanka, Vol. 36, No. 02, pp. 152-156.

23. Structural Appraisal Report, Senarathgama Railway Bridge, Engineering Design Centre, University of Peradeniya, Sri Lanka, 2009.

24. Structural Appraisal Report, Maggona Railway Bridge, Engineering Design Centre, University of Peradeniya, Sri Lanka, 2010.

25. Abeyruwan, H., Dissanayake, U. I., Gallage, D. J., Herath, K. R. B., Herath, S. R., Ranaweera, M. P., Raviprasad, M., \& Vignaraja, M., "Condition Assessment of a Wrought Iron Railway Bridge", Proceedings of the Peradeniya University Research Sessions Sri Lanka. Vol.14, pp. 443-445.

26. Dissanayake, U. I., Abeyruwan, H., Herath, K. R. B., Herath, S. R., Ranaweera, M. P., Nandasena, K. A. D., Gallage, D. J., \& Vignaraja, M., "Condition Evaluation and Determination of Remaining Life of Old Wrought Iron and Steel Railway Bridges in Sri Lanka - a Case Study", Annual Transactions of IESL, 2011, pp. 1-6.

27. Baskaran, K., Karunarathna, W. W. N., \& Hidallana Gamage, H. D., “Finite Element Analysis of Truss Type Steel Bridges", Annual Transactions of IESL, 2011, pp.7-14. 